\title{
Comparative study on management of acute moderate and severe lateral ankle sprain using immobilization in below knee slab versus stirrup ankle brace
}

\author{
Bhandari P S, KC G, Uprety S \\ Department of Orthopaedics and Trauma Surgery, Tribhuvan University Teaching Hospital, Maharajgung, Kathmandu, Nepal
}

Correspondence: Prawesh Singh Bhandari

Email: praweshiom@gmail.com

\begin{abstract}
Introduction: Amongst musculoskeletal injuries, ankle ligament sprains are the single most common sports injury. However, there often appears to be no common regimen for their management, with a wide spectrum of treatment options available. The purpose of this study is to determine the functional outcome of the ankle joint after a moderate or severe inversion injury, comparing standard treatment with a Below Knee Slab Splint against a Stirrup ankle brace.

Method: Prospective study conducted at the emergency department at Tribhuvan University Teaching Hospital. Fifty patients presenting consecutively were randomized into two equal groups: one group was treated with Below Knee Slab Splint and the other with an Stirrup ankle brace. All patients were given a standardized advice sheet referring to rest, ice, compression, and elevation, NSAIDS and support. Patients were reviewed after 48-72 hours, 14 days, and 3 week. Primary outcome measure: Ankle joint function assessed at 3 week using the modified Karlsson scoring method (maximum score 90). Secondary outcome measure: The difference in ankle girth (swelling) at 3 weeks.

Results: Twenty-five patients in Below Knee Slab Splint group and twenty-five patients in the stirrup ankle brace group. The age of the patients ranged from 16 to 55 years with the mean of $30.68 \pm 9.33$ years. The difference in mean age in years was not different in both groups $(\mathrm{P}>0.05)$. The distribution of gender and occupation in both groups were homogeneous $(\mathrm{P}>0.05)$. The karlsson's score mean for brace group is $79.8 \pm 5.3$ and for other group is $72.0 \pm 10.3$ ( $p$-value: 0.002 ). Thus there was a significant difference in Karlssons score between the two groups showing better functional improvement in patients receiving Stirrup ankle brace.There is significant difference in the swelling of clients in between application of the brace $(1.00 \pm 0.48$ and slab $(1.70 \pm 0.50)$ the at end of the third weekwith p value 0.000 .

Conclusion: The use of Stirrup ankle brace for the treatment of lateral ligament ankle sprains produces a significant improvement in ankle joint function at three weeks compared with standard management with aimmobilization in below knee posterior slab splint.
\end{abstract}

Keywords: Ankle Sprain; Below knee slab; Stirrup ankle brace.

\section{Introduction}

In this day of an active, health conscious society, musculoskeletal injuries are becoming more prevalent.
Ankle ligament sprains are the single most common sports injury, accounting for $19-23 \%$ of all sports injuries presenting to accident and emergency (A\&E) departments. It has been estimated that an ankle injury occurs every day 
per 10000 of the population. About $90 \%$ are inversion injuries affecting the lateral ligament complex. Ankle injuries also account for $3-5 \%$ of overall attendances at A\&E departments in Britain and 2-6\% of presentations to emergency departments in the United States. Ankle sprains constitute $4.7-24.4 \%$ of all injuries incurred in an individual sport. Ankle sprains produce $25 \%$ of all time loss due to injury in football, basketball, and crosscountry. ${ }^{1}$ It constitutes approximately one quarter of all musculoskeletal injuries. ${ }^{2}$ In Nepal, however there is no data available pertaining to incidence of ankle injuries and sprains.

A sprain of a ligament is defined as an injury that stretches the fibers of the ligament. In classification system described by Bergfeldet al. ${ }^{2}$ a grade I injury includes a partial tear of the lateral ligament complex. A grade II injury involves decreased motion and some loss of function, a torn anterior talofibular ligament with an intact calcaneofibular ligament, some ligamentous instability (eg, positive anterior drawer and negative talar tilt results), swelling andhemorrhage, and point tenderness. A grade III injury involves almost total loss of function, diffuse swelling and hemorrhage, extreme point tenderness, disruption of the ankle capsule, and a complete tear of the lateral ligament complex as evidenced by marked ligamentous instability (eg, positive anterior drawer and talar tilt test results).

However, despite the high incidence of this injury, there often appears to be no common regimen for their management, with a wide spectrum of treatment options available. But basically treatment modality is non surgical and consists of two different treatment options which are immobilization and the other being functional treatment. Functional treatment consists of a program of early mobilization that may include some initial external support to the ankle. The support may be in the form of an elasticated bandage, strapping, lace-up boots or an external orthotics (Stirrup Brace).The orthotics may prevent inversion/eversion but will allow some degree of flexion/ extension. Immobilization is defined as any therapy that prevents movement of the ankle joint in both flexion/ extension and inversion/eversion. Immobilization consists of immobilization in cast, posterior slab splint or boots. We at our institution commonly immobilize the limb in below knee posterior slab. These management strategies are often passed from senior to junior ranks with only anecdotal evidence to justify their use. With the medical community moving towards the practice of evidence based medicine, research is required to validate current treatment concepts to determine the optimum functional outcome. This study aims to determine the difference in functional outcome between the functional and immobilization as a form of treatment of moderate or severe lateral ankle sprain.

\section{Methods}

The study was conducted in Emergency Department of Tribhuvan University Teaching Hospital during a period of March 2011 to September 2012.

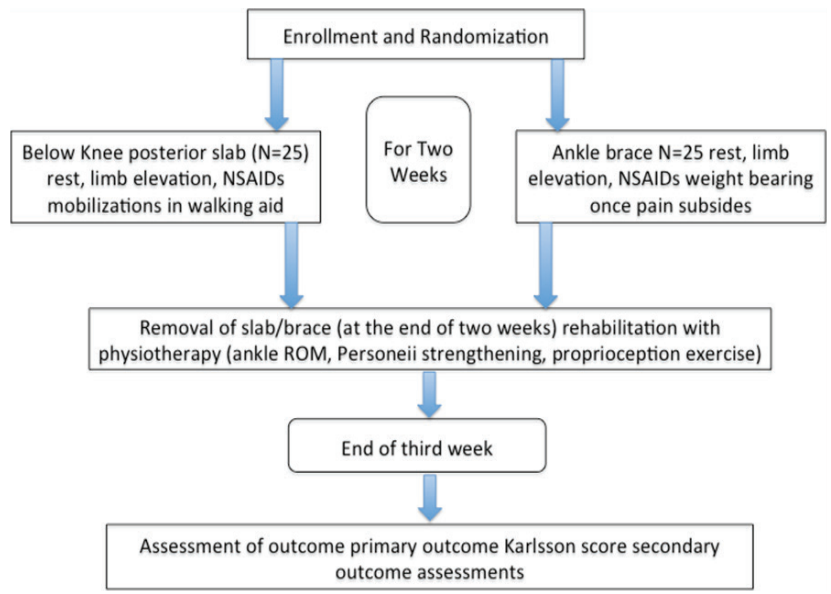

Figure 1: Consort diagram of the study

Fifty patients presenting consecutively within 24 hours of sustaining a moderate or severe lateral ligament sprain after an ankle inversion injury were randomized into two equal groups. For the purpose of this study, the terms mild, moderate, and severe were used corresponding to grades I, II, and III respectively. Fracture was excluded by $\mathrm{x}$ ray examination. Only adults were recruited (aged 16 years and over). After informed written consent was obtained, each patient was allocated to use either a Below Knee Posterior Slab splint (Figure 2) or a Stirrup ankle brace (Figure 3). A standard performa for all patients was completed detailing age, sex, time to presentation, occupation, left or right ankle injured, previous injury, ankle girth. All patients included in the study were given a standardized advice sheet referring to the principles of RICE (rest, ice, compression, and elevation) for use after an acute soft tissue injury. Analgesia and crutches were given as required. Review arrangements were made for 48-72 hours (for assessment of complication due to swelling), two weeks, and three weeks at orthopedics clinic. 

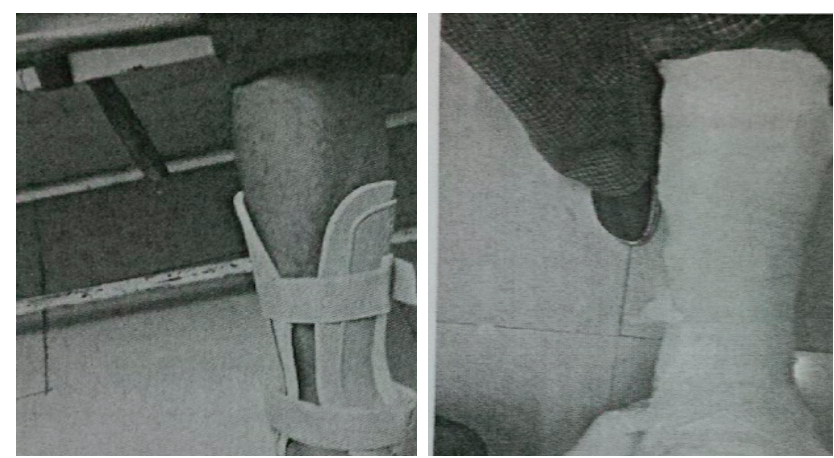

Figure 2: Below knee posterior slab splint Figure 3: Stirrup ankle brace

The inclusion criteria were, first incidence of acute severe lateral ankle sprain following inversion injury of ankle (moderate and severe); presenting within 24h of injury; unable to bear weight on affected limb (Weight-bearing status symptoms severity will be used to indicate severity of sprains, since clinical grading is not possible in the acute phase) and people with flake fractures of less than $3 \mathrm{~mm}$ was be included, because such fractures should be treated as soft-tissue injuries.

Patients with, age less than, 16 years; presenting twenty four hours since injury occurrence; fractures (excluded by ankle AP/LAT / Mortice views); multiple injuries and contraindications to immobilization (eg, high risk of deepvein thrombosis) were excluded.

The primary outcome measured was the ankle joint function. This was assessed at third week using a modified version of the Karlsson scoring scale. ${ }^{4}$ (Table 1) This is a statistically validated scoring scale devised by Karlsson and Peterson and can be used to measure ankle joint function in the rehabilitation phase after an acute ligament injury.

\section{Table 1: The Karlsson scoring scale category}

\begin{tabular}{|c|c|c|}
\hline Category & Degree & Score \\
\hline \multirow[t]{4}{*}{ Pain } & None & 20 \\
\hline & During exercise & 15 \\
\hline & Walking on uneven surfaces & 10 \\
\hline & Walking on even surfaces & 5 \\
\hline \multirow[t]{3}{*}{ Swelling } & None & 10 \\
\hline & After exercise & 5 \\
\hline & Constant & 0 \\
\hline \multirow[t]{4}{*}{ Instability (subjective) } & None & 15 \\
\hline & Walking on uneven surfaces & 15 \\
\hline & Walking on even surfaces & 5 \\
\hline & Constant (severe) using ankle support & 0 \\
\hline \multirow[t]{3}{*}{ Stiffness } & None & 5 \\
\hline & Moderate (morning, after exercise) & 2 \\
\hline & Marked (constant, severe) & 0 \\
\hline \multirow[t]{3}{*}{ Stair climbing } & No problem & 10 \\
\hline & Impaired (instability) & 5 \\
\hline & Impossible & 0 \\
\hline \multirow[t]{3}{*}{ Running } & No problem & 10 \\
\hline & Impaired (instability) & 5 \\
\hline & Impossible & 0 \\
\hline \multirow[t]{4}{*}{ Work Activities } & Same as before injury & 15 \\
\hline & Same work, less sports normal leisure activities & 10 \\
\hline & Light work, no sports, normal leisure activities & 5 \\
\hline & Severely impaired work, decreased leisure activities & 0 \\
\hline \multirow[t]{3}{*}{ Support } & None & 5 \\
\hline & Ankle support during exercise & 2 \\
\hline & Ankle support during daily activities & 0 \\
\hline
\end{tabular}


Secondary outcome measures, (recorded at presentation and at third week)

- The difference in ankle girth (swelling) between the injured/uninjured ankles

Ankle girth was defined as the circumferential measurement of the ankle at the level of both malleoli and noted in centimeters using a tape measure. The difference in the ankle girth between the injured and the uninjured side measured in centimeter is recorded as swelling.

The data were entered in SPSS version 16 and analyzed using this software. The continuous data were expressed as the mean $\pm \mathrm{SD}$ and categorical data were expressed as frequency. The swelling and VAS score were analysed using annova test and Karlssons score was analysesd- using student T-test.The statistical tests were considered significant when the $\mathrm{P}$-value was $<$

\section{Results}

Fifty patients who sustained moderate and severe ankle sprain were enrolled in the study. They were followed up for the period of three week and assessed for functional outcome and decrease in swelling. The distribution of gender and occupation in both were homogeneous $(p>0.05)$. The distribution of ankle sprain in right side by slab was higher than in the group treated by brace.Although the patient with left ankle sprain treated by brace were higher than those treated by slab, this was not statistically significant $(\mathrm{p}>0.05)$.

Table 3: Baseline characteristics of patients enrolled in the study

\begin{tabular}{|c|c|c|c|c|c|c|}
\hline \multirow{2}{*}{ Characteristics } & & \multicolumn{2}{|c|}{ Brace $(\mathrm{n}=\mathbf{2 5})$} & \multicolumn{2}{|c|}{ Slab $(n=25)$} & \multirow{2}{*}{$\mathbf{F}$} \\
\hline & & $\mathbf{N}$ & $\%$ & $\mathbf{n}$ & $\%$ & \\
\hline \multirow[t]{2}{*}{ Sex } & Male & 15 & 30 & 16 & 31 & 0.77 \\
\hline & Female & 10 & 20 & 9 & 18 & \\
\hline \multirow[t]{5}{*}{ Occupation } & Professional & 11 & 22 & 12 & 24 & 0.91 \\
\hline & Student & 6 & 12 & 7 & 14 & \\
\hline & Business & 3 & 6 & 2 & 4 & \\
\hline & Labor & 1 & 2 & 2 & 4 & \\
\hline & Unemployed & 4 & 8 & 2 & 4 & \\
\hline \multirow[t]{2}{*}{ Injury side } & Right & 13 & 26 & 18 & 36 & 0.24 \\
\hline & Left & 12 & 24 & 7 & 14 & \\
\hline Age (mean $\pm \mathrm{SD})$ & & $30.76 \pm 9.70$ & & $30.60 \pm 9.13$ & & 0.95 \\
\hline
\end{tabular}

The Karlsson score mean for brace group was $79.8 \pm 5.3$ and for slab group was $72.0 \pm 10.3$ with (p 0.002). Thus there was a significant difference in Karlssons score between the two groups.

Table 4: Results of Karlsson score

\begin{tabular}{ccc|}
$\begin{array}{c}\text { Type of } \\
\text { support }\end{array}$ & Mean Karlsson's score (sd) & $\begin{array}{c}\text { T- Test P- } \\
\text { Value }\end{array}$ \\
\hline $\begin{array}{c}\text { Brace } \\
\text { Slab }\end{array}$ & $79.8 \pm 5.3$ & 0.002 \\
\hline
\end{tabular}

The mean of swelling before application of any support was not statistically significant between the groups applied with brace and slab with anova test p-value of 0.187 .

The difference of mean of the swelling at 3rd week between the group applied with brace and slab is statistically significant with anova test $p$ value of 0.000 . Thus, there is significant difference in the swelling of patients in between application of the brace and slab.
Table 5: Result of swelling

\begin{tabular}{|c|c|c|c|}
\hline \multirow{2}{*}{ Swelling } & \multicolumn{2}{|c|}{ Type of support } & \multirow{2}{*}{$\begin{array}{c}\text { Anova } \\
\text { test } \\
\text { p-Value }\end{array}$} \\
\hline & Brace & Slab & \\
\hline $\begin{array}{c}\text { At } \\
\text { presentation }\end{array}$ & $2.780 \pm 0.59$ & $3.02 \pm 0.66$ & 0.187 \\
\hline At $3^{\text {rd }}$ Week & $1.00 \pm 0.48$ & $1.70 \pm 0.50$ & 0.000 \\
\hline
\end{tabular}

\section{Discussion}

A sprained ankle is a common injury seen in Emergency departments. However, despite their regular occurrence, management of this injury varies widely between 
Emergency departments and often between clinicians working in the same department. There is as yet no "gold standard" method of management used universally. Instead clinicians rely on a combination of personal experience and clinical judgment.

The use of an ankle orthotics tends to be limited to sports groups or teams that are supervised by either physiotherapists or sports medicine practitioners. Little research has been directed towards management of such injuries in the general population, coordinated through a busy Emergency department where resources will be restricted and orthotic use limited.

Management strategies can be divided into three main categories: cast/splint immobilization, functional treatment (bandage or ankle brace and mobilization) and operative repair. A diverse array of studies is present in the literature comparing one of these methods against another. As a result of the heterogeneous nature of the various research projects they perform poorly under meta-analytical review. It is difficult to compare the results of studies directly, but a few common themes have emerged.

Balancing the advantages and disadvantages of surgical and non-surgical treatment Wolf Petersen et al in their systemic review conclude that the majority of grades I, II and III lateral ankle ligament ruptures can be managed without surgery. The indication for surgical repair should be always made on an individual basis. ${ }^{16}$ We also realized that a majority of investigations included subjects who suffered their first injury combined with subjects who suffered repeated ankle injuries and had associated sequel making it difficult to determine the severity and extent of the injury that was studied. Therefore, the objective of our investigation was to determine the short-term outcome of first-time moderate \& severe ankle sprains and identify the best approach between two approaches to conservative treatment with the goal of returning patients to their preinjury activity levels. The two approaches being immobilization below knee posterior slab and functional treatment with a short period of protection using stirrup ankle brace.

Our study showed that there was statistically significant difference in the functional outcome shown by Karlsson score between the subjects treated with Stirrup ankle brace (79.8 \pm 5.3$)$ compared to subjects treated withbelow knee posterior slab $(72.0 \pm 10.3)$ with p-value of 0.002 at the end of third week. Boyce et al in their study to determine the functional outcome of the ankle joint after a moderate or severe inversion injury in general population, comparing standard treatment with an elastic support bandage against an Aircast ankle brace found the Karlsson score was significantly higher in the Aircast ankle Brace group than

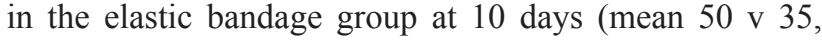
$\mathrm{p}=0.028,95 \%$ confidence interval (ci) 1.7 to 27.7 ) and one month (mean 68 v 55, p $=0.029,95 \%$ ci 1.4 to 24.8 ) (student's t test).1Since both the studies have used brace for a comparable time and period this result aids bracing provides better functional outcome.

A meta-analysis compared immobilization and functional treatment and twenty-one trials met the inclusion criteria and standards. ${ }^{5,6}$ They found no findings concerning outcome in favor of immobilization. However, seven measurements of outcome produced significantly better results in favor of functional treatment. These were: number of patients who returned to sport and work, time to return to sport and work, objective instability, persistent swelling, and patient satisfaction. They concluded that immobilization should no longer be the conservative treatment of choice for patients with acutely sprained ankles. These findings are in line with reviews where time to return to sport/ work was significantly shorter for functional treatment. ${ }^{7-}$ ${ }^{13}$ A multicentre randomised trial with blinded assessment of outcome of 584 participants with severe ankle sprain promoted the use of a cast for treatment of acutely sprained ankles. ${ }^{14}$ But this trial suffers from various shortcomings and failed to compare the different methods of immobilization with the current gold standard, i.e. functional treatment.

Similarly the mean of the swelling at $3^{\text {rd }}$ week between the group applied with brace and slab was statistically significant with anova test ( $p$ value of 0.000 ). Thus there was significant difference in the swelling of patients in between application of the brace and slab. This is most probably because with use of brace patients could easily apply cold compression and movement of the toes and ankle allowed quicker and better mobilization of edema fluids.

A randomised controlled trial of the treatment of inversion injuries using an elastic support bandage or an Aircast ankle brace conducted on 2005 showed no difference between the groups regarding swelling. ${ }^{1}$ The authors have reasoned that the method of assessing ankle girth by manual measurement of the circumference of the joint with a tape measure is open to practical error. More than one investigator measuring the girth introduces the potential for further error. Other more accurate and reproducible methods - for example, volume displacement of water in a "dunk tank" - can be used to calculate swelling, but these are impractical to perform in the emergency departments. 
In our study, a statistically significant improvement in the functional outcome of the ankle joint was present in the stirrup ankle brace group at third week post injury. The Karlsson scoring scale was used, as it provided a practical and reproducible method of assessing ankle joint function. The scale reflects many of the subjective measures that may be considered a determinant of adequate ankle function. We did not analyse the specific components of the score that contributed to the overall differences between the groups. This result only proves that the stirrup ankle brace is superior to an immobilization in below knee posterior slab in determining functional outcome. It does not prove that patients treated with below knee posterior slab derived no benefit. Interestingly, both groups had a high Karlsson score at third week and improvement in with decreased swelling, suggesting that, independent of the treatment used, the injury will improve progressively with time.

This study is limited in its conclusions by several factors. The use of analgesia and crutches was excluded. Analgesic preparations used differed in patients. The prescribing of crutches varied between medical staff, as does the perceived requirement for crutches among patients. Follow up of patients ended after three weeks, but this is longer than routine emergency review. Concern may be raised over the small sample size. There was also difficulty in accurately assessing the grade of ankle sprain based on stress test maneuvers because during acute phase it may not be possible to perform the test due to incurring further pain and spasm of muscles limiting movement. However, this has to be taken into consideration within the limits of performing research in busy emergency departments. Despite the frequency of presentation, patients were often reluctant to be recruited into the study. A long waiting time before being seen by medical staff and the practicalities of travelling to three review clinic appointments in a large geographical area were cited as reasons for nonparticipation. The large proportions of patients that attend emergency departments under the influence of alcohol, drugs, or as the result of violence also affect recruitment. The study could not be truly double blinded.

Although the authors did not know which treatment a patient would receive until the envelope was opened, it was not possible to conceal this at the review clinics, thus introducing an element of possible bias. Although the economic benefits that the use of an ankle brace may produce is out of the remit of this paper, it is important to consider that, although more expensive atsource than an posterior below knee slab support, if patients improve more quickly and return to work earlier, there may be possible economic benefits for the state. One study in 1997 estimated potential financial savings equivalent to US\$8 million per year to the economy if all ankle sprains in Sweden were managed with a brace rather than surgery or cast immobilization. The initial increased cost of bracing would be recouped by achieving return to work half a day earlier. $^{1}$

\section{Conclusion}

The results obtained in this study suggest that the use of an Stirrup ankle brace in the treatment of moderate and severe lateral ligament ankle sprains, presenting within 24 hours of injury, produces a significant improvement in ankle joint function, at third week, compared with standard management with Below knee posterior slab. There is also significant swelling (ankle girth) in patient'streatment with brace. Further research is required on a larger sample group to confirm this hypothesis, with the opportunity of producing a cost effective analysis of any perceived advantages.

\section{References}

1. S H Boyce, M A Quigley, S Campbel Management of ankle sprains: a randomised controlled trial of the treatment of inversion injuries using an elastic support bandage or an Aircast ankle brace Br J Sports Med 2005; 39:91-96. doi: 10.1136/bjsm.

2. Keeman JN. Commentarrenkelspecial. Reuma Trauma. 1990; 1:34-35

3. Bergfeld J, Cox J, Drez D, et al. Symposium: management of acuteankle sprains. ContempOrthop. 1986;13:83-116.003.009233 2

4. Karlsson J, Peterson L. Evaluation of ankle joint function: the use of a scoring scale. The Foot 1991;1:15-19.

5. Kerkhoffs GM, Rowe BH, Assendelft WJ, et al. Immobilisation and functional treat- ment for acute lateral ankle ligament injuries in adults. Cochrane Database Syst Rev 2002;CD003762

6. Kerkhoffs GM, Struijs PA, van Dijk CN. Acute treatment of inversion ankle sprains: immobilization versus functional treatment. ClinOrthopRelat Res 2007;463:250-1.

7. Kannus P, Renstrom P. Treatment for acute tears of the lateral ligaments of the ankle. Operation, cast, or early controlled mobi- lization. J Bone Joint Surg Am 
1991;73: 305-12.

8. Jones MH,Amendola AS. Acute Treatment of Inversion Ankle Sprains: Immobili- zation versus Functional Treatment. ClinOrthopRelat Res 2007;455:169-72.

9. Tiling T, Bonk A, Hoher J, Klein J. Acute injury to the lateral ligament of the ankle joint in the athlete. Chirurg 1994;65:920- 33.

10. Shrier I. Treatment of lateral collateral lig- ament sprains of the ankle: a critical appraisal of the literature. Clin J Sport Med 1995;5:187-95.

11. Pijnenburg AC, van Dijk CN, Bossuyt PM, Marti RK. Treatment of ruptures of the lat- eral ankle ligaments: a meta-analysis. J Bone Joint Surg Am 2000;82:761-73.

12. Ogilvie-Harris DJ, Gilbart M. Treatment modalities for soft tissue injuries of the ankle: a critical review. Clin J Sport Med 1995;5:175-86.

13. Ardevol J, Bolibar I, Belda V, Argilaga S. Treatment of complete rupture of the later- al ligaments of the ankle: a randomized clinical trial comparing cast immobiliza- tion with functional treatment. Knee Surg Sports TraumatolArthrosc 2002;10:371-7

14. Lamb SE, Marsh JL, Hutton JL, et al. Mechanical supports for acute, severe ankle sprain: a pragmatic, multicentre, randomised controlled trial. Lancet 2009; 373:575-81.

15. Callaghan M. Role of ankle taping and bracing in the athlete. Br J Sports Med 1997;31:102-8.

16. Treatment of acute ankle ligament injuries: a systematic revie;Wolf Petersen · Ingo Volker Rembitzki · Andreas GöseleKoppenburg · Andre Ellermann · Christian Liebau · Gerd Peter Brüggemann - Raymond Best Arch Orthop Trauma Surg (2013) 133:1129-1141. 